\title{
Cardiotoxicity Caused by 5 Fluorouracil in a Patient with Adenocarcinoma of Colon.
}

\author{
Rajeeb Kumar Deo ${ }^{1}$, Rishi Khatri ${ }^{1}$, Devendra Khatri ${ }^{1}$, Binod Karki ${ }^{1}$.
}

${ }^{1}$ Department of Internal Medicine, Shree Birendra Hospital, Kathmandu.

\begin{abstract}
From the time of inception, various chemotherapeutic agents are known to cause cardiotoxicity. The cardiotoxicity ranges from mild transient abnormality to irreversible cardiac tissue damage. Certain classes of drugs like anthracyclines are known to be cardiotoxic while some newer drugs like Transtuzumab also cause cardiotoxicity. 5 Fluorouracil is known to be cardiotoxic though the incidence is low. We present a case of cardiotoxicity due to prolonged 5 Fluorouracil infusion in a patient with adenocarcinoma of colon.
\end{abstract}

Keywords: 5-FU, Cardiotoxicity

\section{INTRODUCTION}

Cardiotoxicity is a recognized chemotherapy induced adverse event. Cardiac events associated with chemotherapy vary from mild transient blood pressure and/or electrocardiographic (ECG) changes to more serious arrhythmias, myocarditis, pericarditis, myocardial infarction and cardiomyopathy, which may end in left ventricular dysfunction or congestive heart failure.

Various chemotherapy agents are known to be cardiotoxic. The drugs that predominantly cause irreversible cell destruction due to their cumulative effects, have been designated as type I agents (Table 1), and those without cell destruction as a dominant characteristic are classified as type II agents ${ }^{1}$. Type II agents do not exhibit toxicity that is related to cumulative dose, and their effects are reversible ${ }^{2,3}$.

Though cardiotoxicity due to 5-FU is known, it is not very common. Experience of this toxicity is not reported much in this part of world. The purpose of this case report is to make clinicians familiar about this rare toxicity and to discuss about the ways to try and prevent it.

\section{CASE REPORT}

55 years old male patient presented with history of pain abdomen for 1 year duration. He was evaluated and USG abdomen revealed gall bladder stone. He underwent laparoscopic cholecystectomy however his pain persisted. He was again evaluated and contrast enhanced CT scan of abdomen was done. CT scan revealed mass lesion in the caecum. Patient was evaluated in detail, including cardiac evaluation before surgery. Clinical examination and ECG were normal. However echocardiography was not done. He was taken up for surgery and right hemicolectomy was done. Final biopsy was $\mathrm{Ca}$ Colon-Adenocarcinoma, TNM-pT4bN2bM0., AJCC stage IIIc, Duke stage 3.

In view of advanced stage, he was planned for adjuvant chemotherapy with FOLFOX-4 regimen (Table 2). $\mathrm{He}$ received 1st cycle of chemotherapy without any complications. After 2 days of chemotherapy, patient complained of vague discomfort along with multiple episodes of vomiting. He was managed conservatively with oral medication and recovered well. Second cycle of chemotherapy was started after 14 days according to schedule. Day 1 of chemotherapy, which included oxaliplatin followed by rapid infusion of Leucovorin $\& 5$-FU, followed by 22 hours of 5-FU infusion, was uneventful. However on day 2, 1 hour after starting planned for 22 hours infusion of 5-FU, patient complained of dull aching persisting pain over left shoulder. Injection Tramadol was given IV and infusion was stopped. However pain persisted and he complained of vague discomfort over left precordium also. ECG was done which showed ST-T changes consistent with acute myocardial injury (Figure 1). Cardiac enzymes (CKNAC and CK-MB) as well as Troponin I were negative. Cardiologist consultation was sought. Echocardiography was done which revealed global hypokinesia, mild MR, absent a wave in mitral inflow, LV systolic dysfunction

\section{Correspondence:}

Lt. Col. Dr. Rajeeb Kumar Deo

Department of Internal Medicine

Shree Birendra Hospital, Kathmandu, Nepal.

Email: rajeebdeo@yahoo.com 
Table 1: Cardiotoxic chemotherapeutic agents

\begin{tabular}{|l|l|}
\hline \multicolumn{1}{|c|}{ Type I agents } & \multicolumn{1}{c|}{ Type Il agents } \\
\hline Doxorubicin & Transtuzumab \\
\hline Daunorubicin & Sunitinib \\
\hline Epirubicin & Lapatinib \\
\hline Idarubicin & \\
\hline Mitoxantrone & \\
\hline Cyclophosphamide & \\
\hline
\end{tabular}

* Does not include all potential cardiotoxic chemotherapeutic agents.

Table 2: FOLFOX-4 Regimen

\begin{tabular}{|c|c|c|c|}
\hline Drug & Dose & Days & Duration \\
\hline Oxaliplatin & $85 \mathrm{mg} / \mathrm{m}^{2}$ & D 1 & Over 2 hrs \\
\hline$\overline{\text { Leucovorin }}$ & $200 \mathrm{mg} / \mathrm{m}^{2}$ & $\bar{D} 1+\mathrm{D} 2$ & Over 30 mins \\
\hline $5-\mathrm{FU}$ & $400 \mathrm{mg} / \mathrm{m}^{2}$ & D $1+D 2$ & Over 30 mins \\
\hline $5-\mathrm{FU}$ & $600 \mathrm{mg} / \mathrm{m}^{2}$ & $\mathrm{D} 1+\mathrm{D} 2$ & 22 hrs infusion \\
\hline
\end{tabular}

with ejection fraction of $45 \%$. Patient was admitted in ICU and managed conservatively. Serial cardiac enzymes were normal. Follow up ECG showed gradual normalization (Figure 2-5). Patient was kept on regular follow up. ECG (Figure 6) and ECHO done after 6 weeks were normal. He is now on 3 weekly CAPOX regimen (Capecitabine + Oxaliplatin). He has completed 2 cycles and is on continued followup.

\section{DISCUSSION AND REVIEW}

OF LITERATURE

As early as 1967, there were reports of heart failure in children treated with doxorubicin ${ }^{4}$. Since then the cytostatic antibiotics of the anthracycline class remain the most common cardiotoxic chemotherapeutic agents.

5-FU is administered widely for varied types of malignancies like gastrointestinal, breast, and head \& neck cancer. Common adverse clinical reactions such as myelosuppression, diarrhea, and mucositis have been shown to be related to the modalities of 5-FU administration like dose, schedule, or route ${ }^{5}$. For instance, in similar doses of 5-FU given by continuous intravenous infusion instead of bolus injection, the continuous intravenous infusion provoked less hematotoxicity but caused more mucositis and palmo-plantar dysesthesia6.

Apart from these toxicities, 5-FU is also known to cause cardiotoxicity. Gradishar and Vokes stated that highdose 5 -FU therapy $(>800 \mathrm{mg} / \mathrm{m} 2 / \mathrm{d})$ is associated with up to $10 \%$ of cardiac events ${ }^{7}$. Labianca reported cardiac toxicity in $1.6 \%$ of patients who were treated with 5-FU8. The study done by de Forni confirmed significant incidence $(7.6 \%)$ of 5 -FU cardiotoxicity following high dose continuous infusion ${ }^{9}$. 5-FU cardiotoxicity is more common in patients with a history of coronary artery disease $\mathrm{s}^{5,10,11}$.

Although the clinical features of 5-FU cardiotoxicity are recognized widely now, the underlying physiopathology of this syndrome has not been demonstrated clearly. Various hypotheses have been proposed, which include ischemia secondary to coronary artery spasm, a direct toxicity on the myocardium, 5-FU interactions with the coagulation system, and an immune-allergic phenomena ${ }^{12}$. The study done by de Forni suggested that 5-FU cardiotoxicity closely resembles the stunned myocardium syndrome and might be related to a diffuse ischemia or a direct toxicity ${ }^{8}$.

\section{CONCLUSION}

Prophylaxis against 5-FU cardiotoxicity starts with identifying patients with underlying coronary artery disease and avoiding regimens that contain continuous 5 -FU infusion in this group. Using IV bolus administration rather than continuous administration may be advisable but benefit of continuous 5-FU infusion cannot be over emphasized.

\section{REFERNECES}

1. Ewer MS, Lippman SM. Type II chemotherapy-related cardiac dysfunction: time to recognize a new entity. J. Clin. Oncol. 2005;23:2900-02.

\section{4}

M e d i c a 1 J o u r n a

of

S h r e e

B i r e n d r a

Ho s p i t a 1 
MJSBH January-June 2013|Vol 12| Issue 1

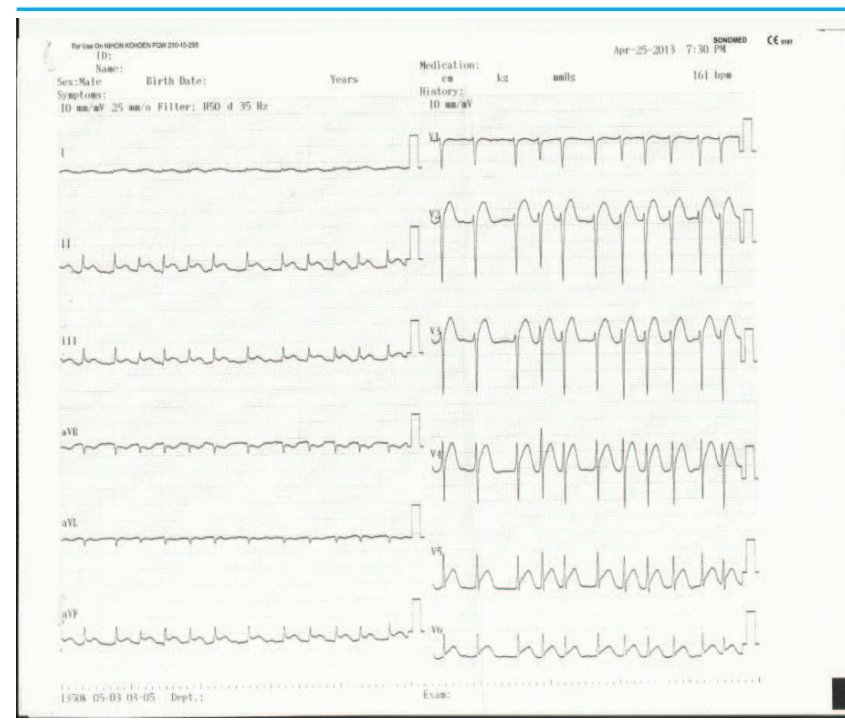

Figure 1: At the time of onset

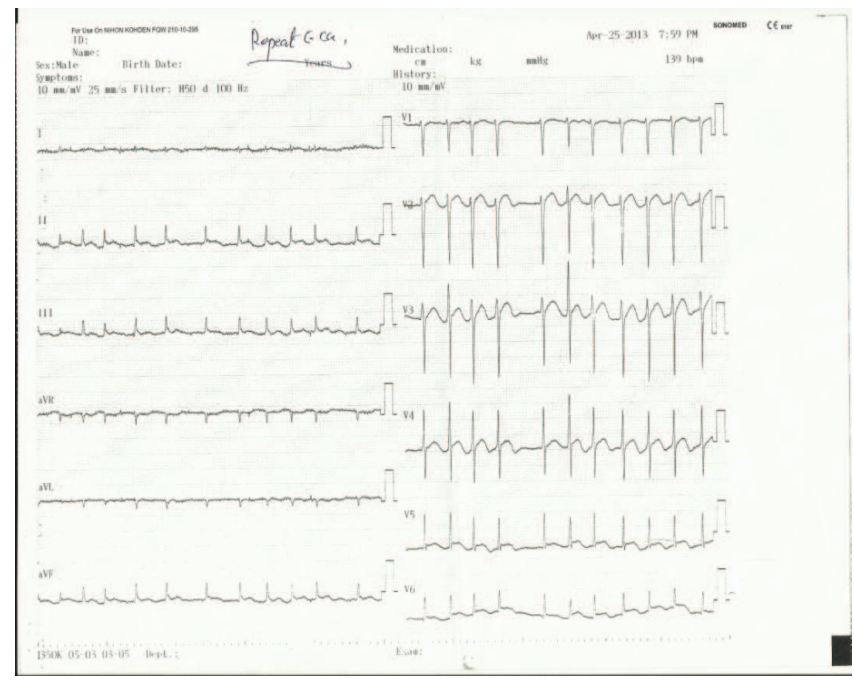

Figure 2: After 15 minutes

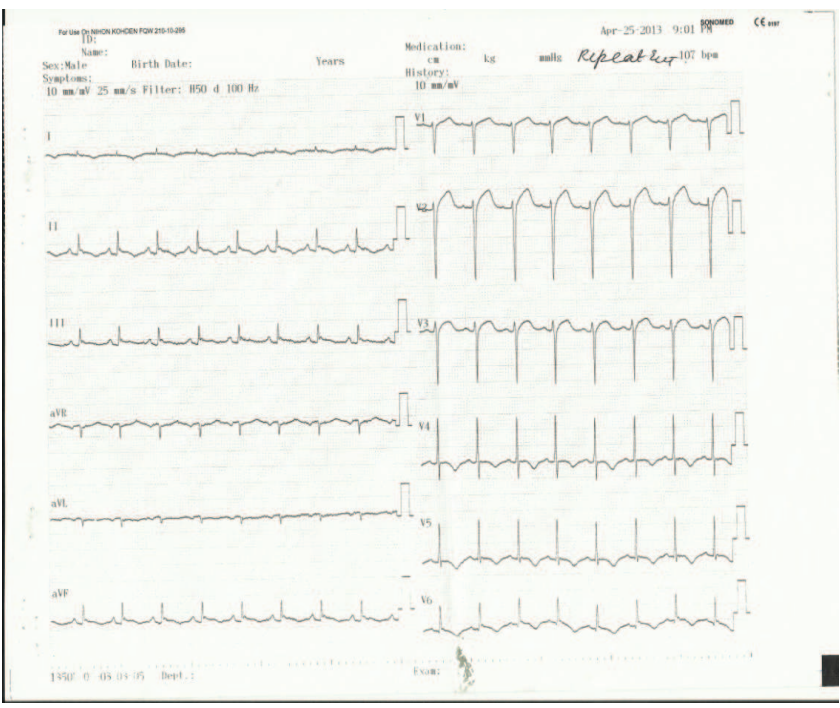

Figure 3: After 1hour 30 mins

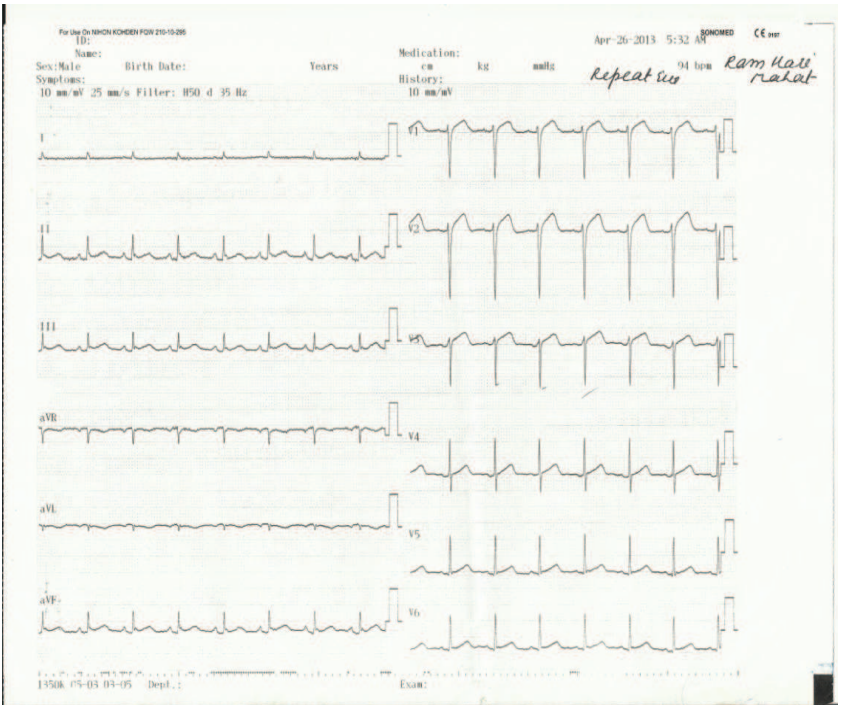

Figure: After 10 hrs

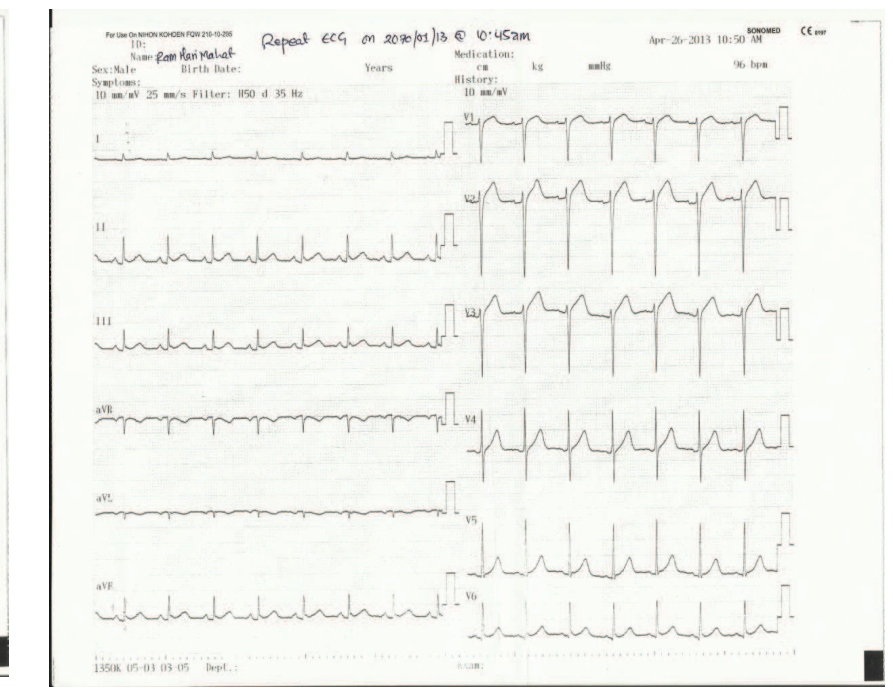

Figure 5: After 15 hours

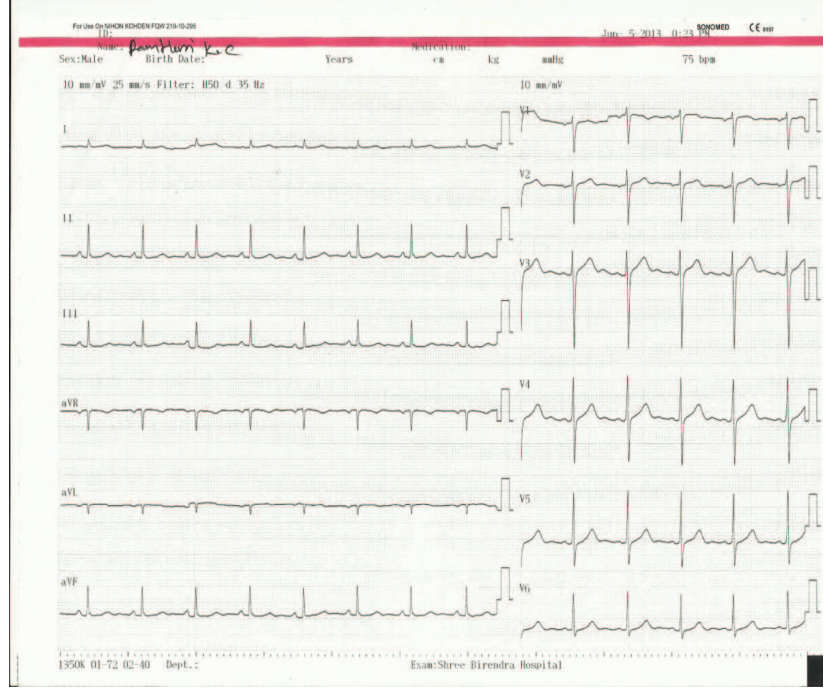

Figure 6: After 6 weeks

Me dical Journa 1 of S h re e B i r e nd ra Hos pit a 1 

col.1989; 7:425-432.

2. Tan-Chiu E, Yothers G, Romond E, Geyer CE Jr, Ewer M, Keefe Det al. Assessment of cardiac dysfunction in a randomized trial comparing doxorubicin and cyclophosphamide followed by paclitaxel, with or without trastuzumab as adjuvant therapy in node-positive, human epidermal growth factor receptor 2-overexpressing breast cancer: NSABP B-31. J. Clin. Oncol. 2005;23:7811-9.

3. Suter TM, Procter M, van Veldhuisen DJ, Muscholl M, Bergh J, Carlomagno Cet al. Trastuzumab-associated cardiac adverse effects in the Herceptin Adjuvant Trial. J. Clin. Oncol. 2007;25:3859-65.

4. Tan C, Tasaka H, Yu KP, Murphy ML, Karnofsky DA. Daunomycin, an antitumor antibiotic, in the treatment of neoplastic disease: clinical evaluation with special reference to childhood leukemia. Cancer.1967; 20:333-53.

5. Grenn JL. Fluorinated pyrimidines, in Chabner BA, Collins JM (eds): Cancer Chemotherapy, Principles and Practice. Philadelphia,PA, Lippincott, 1990, pp 197-200.

6. Lokich JJ, Ahlgren JD, Gullo JJ. A prospective randomized comparison of continuous infusion fluorouracil with a conventional bolus schedule in metastatic colorectal carcinoma: A Mid-Atlantic Oncology Program study. J ClinOn-
7. Gradishar WJ, Vokes EE. 5-Fluorouracil cardiotoxicity: A critical review. Ann Oncol. 1990; 1:409-414.

8. Labianca R, Beretta G, Clerici M, Fraschini P, Luporini G. Cardiac toxicity of 5-fluorouracil: a study on 1083 patients. Tumori 1982; 68:505-10.

9. de Forni M, Malet-Martino MC, Jaillais P, Shubinski RE, Bachaud JM, Lemaire L et al. Cardiotoxicity of high-dose continuous infusion fluorouracil: a prospective clinical study. J ClinOncol. 1992;10:1795-801.

10. Patel B, Kloner RA, Ensley J, Al Sarraf M, Kish J, Wynne J. 5-Fluorouracil cardiotoxicity: left ventricular dysfunction and effect of coronary vasodilators. Am J Med Sci. 1987; 294:238-43.

11. Rezkalla S, Kloner RA, Ensley J, Al-Sarraf M, Revels $S$, Olivenstein A et al. Continuous ambulatory ECG monitoring during fluorouracil therapy: a prospective study. J ClinOncol.1989; 7:509-14.

12. Freeman NJ, Costanza ME. 5-Fluorouracil-associated cardiotoxicity. Cancer. 1988; 61:36-45. 